Case Report

\title{
Giant Congenital Melanocytic Naevus with Proliferative Nodules Mimicking Congenital Malignant Melanoma: A Case Report and Review of the Literature of Congenital Melanoma
}

\author{
Massimiliano Scalvenzi, ${ }^{1}$ Franco Palmisano, ${ }^{1}$ Sara Cacciapuoti, ${ }^{1}$ Fiorella Migliaro, ${ }^{2}$ \\ Maria Siano, ${ }^{3}$ Stefania Staibano, ${ }^{3}$ Luigi Tornillo, ${ }^{4}$ and Claudia Costa ${ }^{1}$ \\ ${ }^{1}$ Department of Dermatology, Federico II University, via Pansini 5, 80131 Naples, Italy \\ ${ }^{2}$ Department of Neonatal Intensive Care, Federico II University, via Pansini 5, 80131 Naples, Italy \\ ${ }^{3}$ Department of Biomorphological and Functional Science, Federico II University, via Pansini 5, 80131 Naples, Italy \\ ${ }^{4}$ Institute of Pathology, University of Basel, 4003 Basel, Switzerland \\ Correspondence should be addressed to Massimiliano Scalvenzi; scalvenz@unina.it
}

Received 26 November 2012; Accepted 24 December 2012

Academic Editors: S. A. Cuevas-Covarrubias, M. J. Fellner, S. Inui, K. Jimbow, and K. E. Sharquie

Copyright (C) 2013 Massimiliano Scalvenzi et al. This is an open access article distributed under the Creative Commons Attribution License, which permits unrestricted use, distribution, and reproduction in any medium, provided the original work is properly cited.

\begin{abstract}
Congenital malignant melanoma (CMM) is a rare condition that is defined as malignant melanoma recognized at birth. CMM may develop in utero in one of three ways: (1) transmission by metastasis through the placenta from a mother with melanoma; (2) primary melanoma arising within a giant congenital melanocytic naevus (GCMN); (3) primary de novo cutaneous CMM arising in utero. CMM can be confused clinically and histologically with benign proliferative melanocytic lesions such as giant congenital nevi. We describe the case of a patient presenting a GCMN with proliferative nodules, clinically and dermoscopically resembling a $\mathrm{CMM}$, demonstrating the importance of caution in making a diagnosis of $\mathrm{MM}$ and highlighting the possibility that benign lesions as GCMN can mimic a malignant melanoma in this age group.
\end{abstract}

\section{Case Report}

A 7-day-old Italian male child showed at birth a dark, irregular, and raised skin lesion measuring $8 \times 11 \mathrm{~cm}$ located on the back (Figure 1). He was born full-term by cesarean delivery. The birth weight was $3200 \mathrm{~g}$. He appeared otherwise healthy with no evidence of lymphadenopathy or organomegaly, with an Apgar score of 10. The mother was 30, and she was healthy and received no pharmacological therapies during the pregnancy. There were no maternal suspicious lesions. One month before the delivery, a presumable angiomatous lesion was diagnosed by prenatal ecography. No history of melanoma was known in the family. There were two brothers, without any disease. At the age of 7 days, he was seen at the Department of Dermatology of Federico II of Naples because, according to clinical features of the lesion, there was a very strong suspect of melanoma. A careful dermoscopic examination was performed, which revealed irregular pigmentation, atypical pigment network, irregular dots and globules, irregular streaks, and a wide blue-whitish veil (Figure 2). On the seventh and fourteenth days of life, 4 biopsy specimens of the flat and the raised areas were taken. The specimens were fixed in formalin and sent for histologic analysis. All specimens demonstrated similar histologic features. There was (Figures 3(a), 3(b), and 3(c)) a dermic component characterized by a solid growth pattern with deep melanocytic nodules showing a high hypercellularity with no significant atypia. The melanocytes were densely packed and uniform in nature exhibiting a small nucleus, sometimes with fine nucleoli. Nuclear pleomorphism was not seen. The immunohistochemical stains showed a strong positivity for S-100 protein (Figure 3(d)) and ki67 (Figure 3(e)), while 


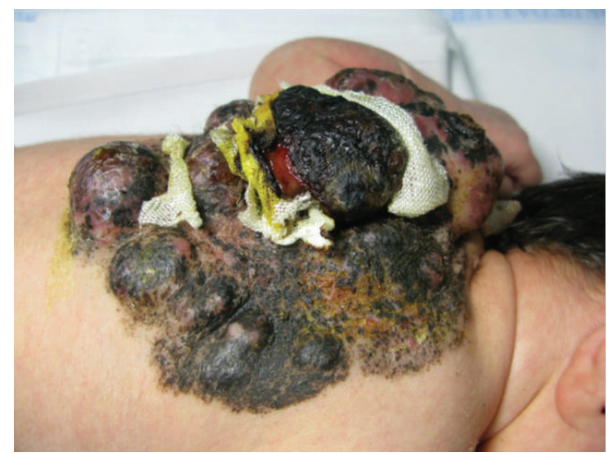

FIGURE 1: Clinical appearance of a dark, irregular, and raised skin lesion measuring $8 \times 11 \mathrm{~cm}$ located on the back.

the HMB-45 (human black melanoma 45) staining was negative (Figure 3(f)). A diagnosis of a giant congenital nevus with proliferative dermic nodules was made. There was no histologic evidence of melanoma. A magnetic resonance imaging was performed in order to exclude the presence of brain and spine lesions that can be associated with congenital melanocytic nevus. No leptomeningeal pigmentations or nevi were found in brain and spine. The patient underwent a three-time plastic surgery operation in April, June, and September 2010 that resulted in a complete excision of the lesion (Figure 4). No skin-grafting or cutaneous expander was needed. During a follow-up period of 2 years, this child remained well, with no evidence of malignancy.

\section{Discussion and Review}

Congenital melanocytic nevi are present at birth in $1 \%$ to $2 \%$ of newborns [20], and GCMN, defined as greater than $20 \mathrm{~cm}$ in diameter, has a $2 \%$ to $42 \%$ risk of malignant transformation, with a $6 \%$ to $14 \%$ lifetime risk of developing melanoma [20, 21].

Discrete dermal nodular proliferations commonly referred to as "proliferative nodules" [22], "atypical dermal nodules" [23], "atypical epithelioid tumors in congenital nevi" [24], or "proliferative dermal lesions" [25] can be identified in congenital nevi.

Both clinical management and histopathologic interpretation of atypical proliferations in congenital melanocytic nevi pose significant challenges to dermatologists and pathologists [20].

The true incidence of CMM is difficult to determine due to small number of reported cases and problems associated with diagnosis, and it is likely that some of the cases described as "congenital melanoma" may have been undiagnosed GCMN.

CMM is extremely rare. From our review of the available literature, twenty cases of CMM have been reported in the English medical literature since 1925 (Table 1).

Of the 20 children, 12 were males and 4 females (in 4 cases the sex was not reported). Four of the cases were transplacental metastatic melanomas, 9 GCMN-associated melanoma, and 7 de novo melanoma.

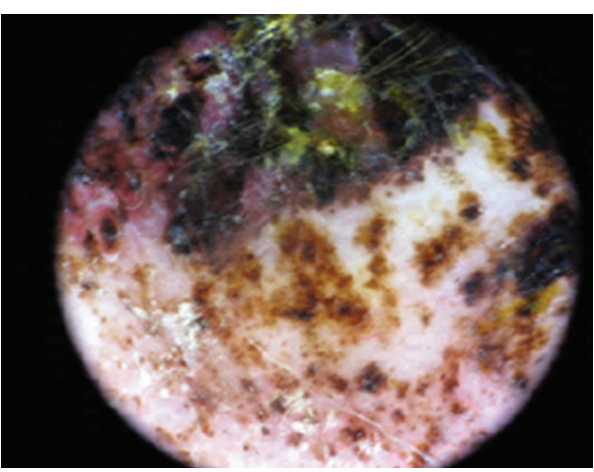

(a)

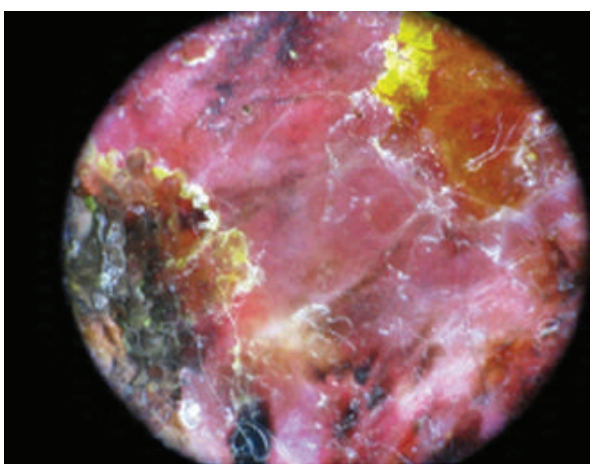

(b)

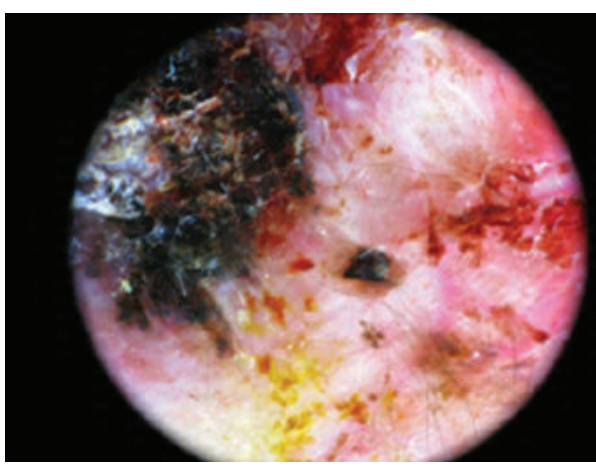

(c)

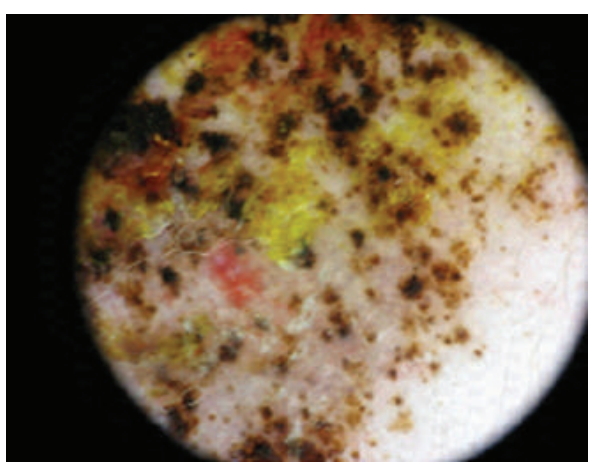

(d)

Figure 2: Dermoscopic features. An irregular pigmentation (a-d), atypical pigment network $(a-d)$, irregular dots and globules $(a-d)$, irregular streaks $(\mathrm{a}-\mathrm{c})$, and a wide blue-whitish veil $(\mathrm{a}-\mathrm{c})$ are clearly visible. 

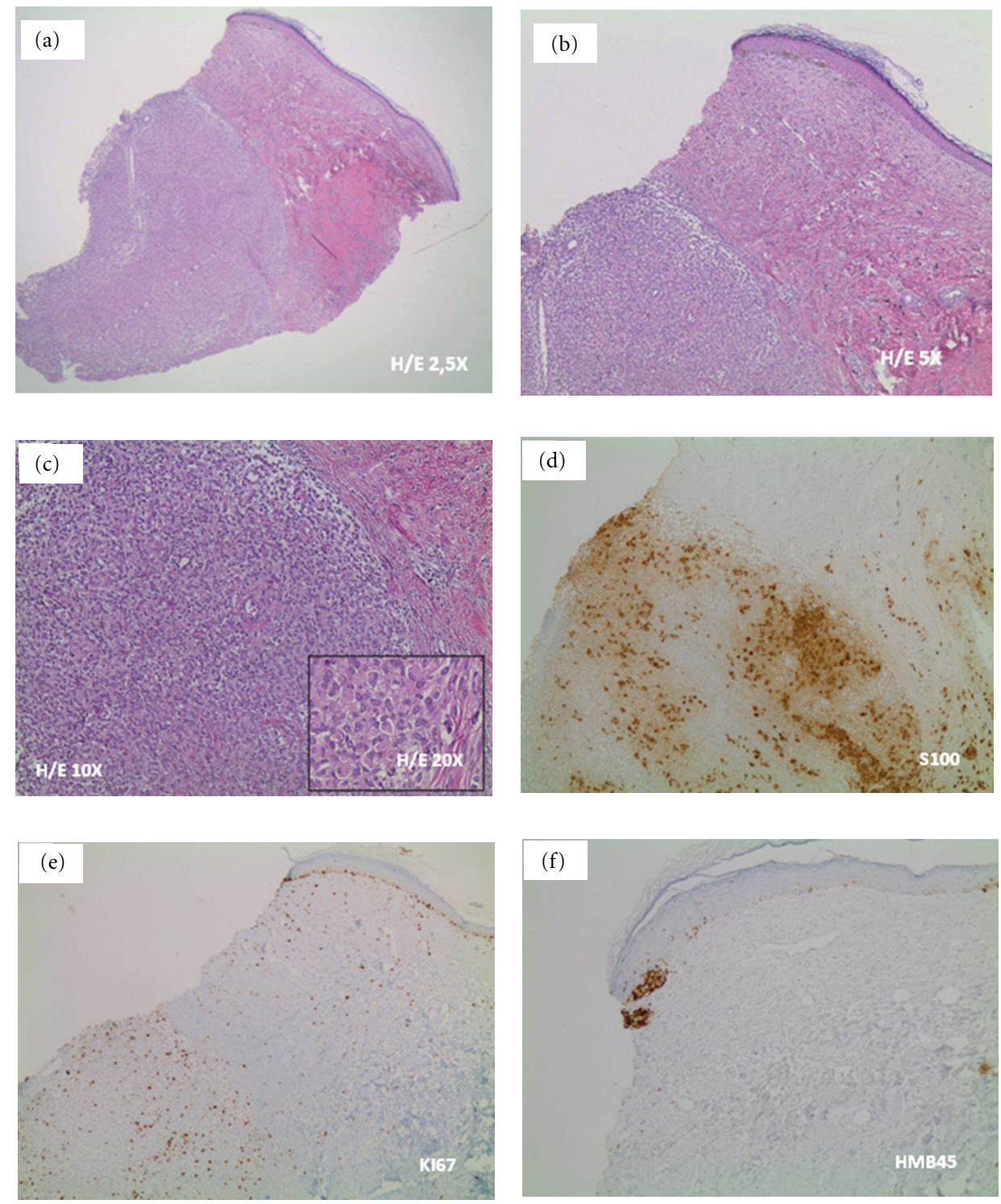

FIGURE 3: Histopathologic features. We can see $(\mathrm{a}-\mathrm{c})$ a dermic component characterized by a solid growth pattern with deep nodules showing a high hypercellularity with no significant atypia. These melanocytes are densely packed and uniform in nature exhibiting a small nucleus; some cells have fine nucleoli. Nuclear pleomorphism is not seen. Immunohistochemical stains. It is visible a strong positivity for S-100 protein (d) and ki67 (e) but a negativity for the HMB-45 (human black melanoma 45) (f). Abbreviations. H/E: hematoxylin and eosin.

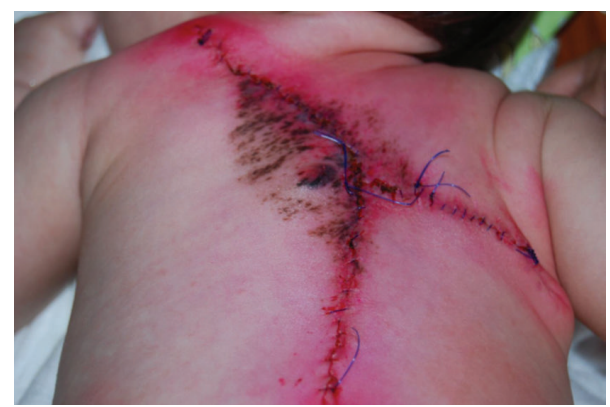

FIGURE 4: Clinical appearance of the patient after a three-time plastic surgery operation. No skin-grafting or cutaneous expander was needed.
Weber et al. in 1930 [15] and Holland in 1949 [16] reported the first CMM arising from maternal malignant melanoma via placental metastasis. Fetal metastasis is extremely rare, and it has been reported that there is about $25 \%$ risk of melanoma with placental metastasis spreading from mother to fetus [26-28]. Of course, in such cases the diagnosis is relatively easy.

Nine neonatal melanomas developed within a GCMN or preexisting nevus; there was evidence of metastasis or local spread in 4 of these patients, 3 of whom subsequently died [29].

The other seven cases arose on apparently normal skin, and 3 of these ended in demise of the patient [29]. 
TABLE 1: Review of neonatal malignant melanoma.

\begin{tabular}{|c|c|c|c|c|c|c|}
\hline Case & Authors & Aetiology & Age at diagnosis & Sex & Location of Lesion & Outcome \\
\hline 1 & Coe $[1], 1925$ & de novo & $\begin{array}{l}\text { Present at birth, } \\
\text { diagnosed } 8 \mathrm{wk}\end{array}$ & $\mathrm{F}$ & Head & D $10 \mathrm{mo}$ \\
\hline 2 & Sweet and Connerty [2], 1941 & de novo & $\begin{array}{l}\text { Present at birth, } \\
\text { diagnosed } 7 \mathrm{~d}\end{array}$ & M & Buttocks & D $17 \mathrm{~d}$ \\
\hline 3 & Stromberg [3], 1979 & de novo & $\begin{array}{l}\text { Present at birth, } \\
\text { diagnosed } 5 \text { mo }\end{array}$ & No data & Mastoid process & A $18 y$ \\
\hline 4 & Hayes and Green [4], 1984 & de novo & At birth & M & Disseminated tumor & A 5 y $10 \mathrm{mo}$ \\
\hline 5 & Prose et al. [5], 1987 & de novo & $6 \mathrm{wk}$ & $\mathrm{F}$ & Abdomen & A $1 y$ \\
\hline 6 & Song et al. [6], 1990 & de novo & At birth & M & Occiput & $\mathrm{D} 2 \mathrm{~h}$ \\
\hline 7 & Asai et al. [7], 2004 & de novo & $2 \mathrm{mo}$ & M & Right thumb & A $3 y$ \\
\hline 8 & Oldhoff and Koudstaal [8], 1968 & GCMN & At birth & M & Right thigh & A $10 y$ \\
\hline 9 & Stronmberg [3], 1979 & GCMN & At birth & M & Temple & A $6 \mathrm{mo}$ \\
\hline 10 & Campbell et al. [9], 1987 & GCMN & In utero & M & Mass over spine & $\mathrm{D} 17 \mathrm{~min}$ \\
\hline 11 & Naraysingh and Busby [10], 1986 & GCMN & At birth & M & $\begin{array}{l}\text { Extensive over back } \\
\text { containing tumor } \\
\text { nodules; multiple } \\
\text { satellite lesions }\end{array}$ & D 6 wk \\
\hline 12 & Mancianti et al. [11], 1990 & GCMN & $8 \mathrm{wk}$ & No data & Right thigh & A $41 \mathrm{mo}$ \\
\hline 13 & Mancianti et al. [11], 1990 & GCMN & $3 \mathrm{wk}$ & No data & $\begin{array}{l}\text { Bathing-trunk nevus } \\
\text { with nodules }\end{array}$ & A $18 \mathrm{mo}$ \\
\hline 14 & Baader et al. [12], 1992 & GCMN & At birth & $\mathrm{F}$ & $\begin{array}{l}\text { Thoracolumbar and } \\
\text { gluteal }\end{array}$ & A 4 mo \\
\hline 15 & Ishii et al. [13], 1991 & GCMN & $\begin{array}{l}\text { Present at birth, } \\
\text { diagnosed } 40 \mathrm{~d}\end{array}$ & M & Left thigh & D $18 \mathrm{mo}$ \\
\hline 16 & Koyama et al. [14], 1996 & GCMN & At birth & $\mathrm{F}$ & Scalp with nodules & No data \\
\hline 17 & $\begin{array}{l}\text { Weber et al. [15] 1930, Holland } \\
\text { [16], } 1949\end{array}$ & Transplacental & $8 \mathrm{mo}$ & M & $\begin{array}{c}\text { Generalized } \\
\text { subcutaneous nodules }\end{array}$ & D $10 \mathrm{mo}$ \\
\hline 18 & Campbell et al. [9], 1987 & Transplacental & $5 \mathrm{mo}$ & No data & Left upper quadrant & $\mathrm{D}$ \\
\hline 19 & Dargeon et al. [17], 1950 & Transplacental & $9 \mathrm{mo}$ & M & Preauricular & D $11 \mathrm{mo}$ \\
\hline 20 & Brodsky et al. [18], 1965 & Transplacental & $11 \mathrm{~d}$ & M & $\begin{array}{l}\text { Cord blood showed } \\
\text { malignant cells; } \\
\text { multiple lesions on } \\
\text { chest wall }\end{array}$ & D 7 wk \\
\hline
\end{tabular}

Abbreviations. GCMN: giant congenital melanocytic nevus; A: alive; D: dead; min: minutes; h: hours; d: days; wk: weeks; mo: months; y: years.

GCMN is a great mimicker of malignant melanoma; clinical indicators such as changes in colour, size, shape, rapid growth rate, nodularity, and even ulceration may occur in this benign lesion. Moreover, melanoma-specific dermoscopic criteria may also be present (Table 2).

Histologic features recognized as evidence of malignancy like mitotic activity, nuclear pleomorphism, and pagetoid melanocytic proliferation may also be present in a GCMN [29]. Malignant change, however, is exceptional in neonates.

Previous reports have recognized benign proliferative nodules within GCMNs that behave in a nonaggressive manner [11, 30-32]. Despite their clinically and dermoscopically alarming appearance, in time, these nodules may reduce in size, become softer, and even regress completely, and the histologic features become less worrisome [1, 17, 32].

Based on the excellent prognosis of many reported cases, we believe that some previously reported cases of CMM were not malignant lesions.
We believe that our case represents benign large dermal nodules within GCMN that clinically and dermoscopically resembled a malignant melanoma.

Dermoscopy is a very useful technique for the analysis of pigmented lesions; it represents a link between clinical and histological views, affording an earlier diagnosis of skin melanoma.

It also helps in the diagnosis of many other pigmented skin lesions that can mimic melanoma, such as seborrheic keratosis, pigmented basal cell carcinoma, haemangioma, blue naevus, atypical naevus, and benign naevus.

Cutaneous melanoma can show a multiplicity of characteristics like dermoscopic variation of colours and structures and asymmetry. Dermoscopy facilitates diagnostic suspicion, and can predict the depth of the tumor; for example, melanoma in situ and melanoma with dermal invasion exhibit visible differences on close examination. Obviously, 
TABle 2: Seven melanoma-specific dermoscopic criteria [19]. As our case reports, a GCMN may show these features.

\begin{tabular}{|c|c|c|}
\hline Criterion & Definition & Histopathologic correlates \\
\hline (1) Atypical pigment network & $\begin{array}{l}\text { Black, brown, or gray network } \\
\text { with irregular meshes and thick } \\
\text { lines }\end{array}$ & $\begin{array}{l}\text { Irregular and broadened rete } \\
\text { ridges }\end{array}$ \\
\hline (2) Blue-whitish veil & $\begin{array}{l}\text { Irregular, confluent, gray-blue to } \\
\text { whitish-blue diffuse } \\
\text { pigmentation }\end{array}$ & $\begin{array}{l}\text { Acanthotic epidermis with focal } \\
\text { hypergranulosis above sheets of } \\
\text { heavily pigmented melanocytes } \\
\text { in the dermis }\end{array}$ \\
\hline (3) Atypical vascular pattern & $\begin{array}{l}\text { Linear-irregular or dotted vessels } \\
\text { not clearly combined with } \\
\text { regression structures }\end{array}$ & Neovascularization \\
\hline (4) Irregular streaks & $\begin{array}{l}\text { Irregular, more or less confluent, } \\
\text { linear structures not clearly } \\
\text { combined with pigment network } \\
\text { lines }\end{array}$ & $\begin{array}{l}\text { Confluent junctional nests of } \\
\text { melanocytes }\end{array}$ \\
\hline (5) Irregular pigmentation & $\begin{array}{l}\text { Black, brown, and/or gray } \\
\text { pigmented areas with irregular } \\
\text { shape and/or distribution }\end{array}$ & $\begin{array}{l}\text { Hyperpigmentation throughout } \\
\text { the epidermis and/or upper } \\
\text { dermis }\end{array}$ \\
\hline (6) Irregular dots/globules & $\begin{array}{l}\text { Black, brown, and/or gray round } \\
\text { to oval, variously sized structures } \\
\text { irregularly distributed within the } \\
\text { lesion }\end{array}$ & $\begin{array}{l}\text { Pigment aggregates within } \\
\text { stratum corneum, epidermis, } \\
\text { dermoepidermal junction, or } \\
\text { papillary dermis }\end{array}$ \\
\hline (7) Regression structures & $\begin{array}{l}\text { White areas (white scarlike areas) } \\
\text { and blue areas (gray-blue areas, } \\
\text { peppering, multiple blue-gray } \\
\text { dots) may be associated, thus } \\
\text { featuring so-called blue-whitish } \\
\text { areas virtually indistinguishable } \\
\text { from blue-whitish veil }\end{array}$ & $\begin{array}{l}\text { Thickened papillary dermis with } \\
\text { fibrosis and/or variable amounts } \\
\text { of melanophages }\end{array}$ \\
\hline
\end{tabular}

its findings have to be confirmed by histopathologic examination [33].

Based on our experience and the literature review, we believe that although a lesion can appear alarming, extreme caution is needed in diagnosing a melanoma in an otherwise healthy neonate.

This paper underlines the importance of a proper diagnosis, for which the histopathological analysis is fundamental; misdiagnosis may lead to anxiety and unnecessary treatment, like chemotherapy and surgical amputations.

\section{Conflict of Interests}

The authors declare that they have no conflict of interests.

\section{References}

[1] H. E. Coe, "Malignant pigmented mole in an infant," Northwest Medicine, vol. 24, pp. 181-182, 1925.

[2] L. K. Sweet and H. V. Connerty, "Congenital melanoma: report of a case in which antenatal metastasis occurred," American Journal of Diseases of Children, vol. 62, pp. 1029-1040, 1941.

[3] B. V. Stromberg, "Malignant melanoma in children," Journal of Pediatric Surgery, vol. 14, no. 4, pp. 465-467, 1979.

[4] F. A. Hayes and A. A. Green, "Malignant melanoma in childhood: clinical course and response to chemotherapy," Journal of Clinical Oncology, vol. 2, no. 11, pp. 1229-1234, 1984.
[5] N. S. Prose, T. A. Laude, E. R. Heilman, and C. Coren, "Congenital malignant melanoma," Pediatrics, vol. 79, no. 6, pp. 967-971, 1987.

[6] K. Y. Song, H. G. Song, J. G. Chi, and J. G. Graham, "Congenital malignant melanoma: a case report," Journal of Korean Medical Science, vol. 5, no. 2, pp. 91-95, 1990.

[7] J. Asai, H. Takenaka, S. Ikada, F. Soga, and S. Kishimoto, "Congenital malignant melanoma: a case report," British Journal of Dermatology, vol. 151, no. 3, pp. 693-697, 2004.

[8] J. Oldhoff and J. Koudstaal, "Congenital papillomatous malignant melanoma of the skin," Cancer, vol. 21, no. 6, pp. 1193-1197, 1968.

[9] W. A. Campbell, E. Storlazzi, and A. M. Vintzileos, "Fetal malignant melanoma: ultrasound presentation and review of the literature," Obstetrics and Gynecology, vol. 70, no. 3, pp. 434-439, 1987.

[10] V. Naraysingh and G. O. D. Busby, "Congenital malignant melanoma," Journal of Pediatric Surgery, vol. 21, no. 1, pp. 81-82, 1986.

[11] M. L. Mancianti, W. H. Clark, F. A. Hayes, and M. Herlyn, "Malignant melanoma simulants arising in congenital melanocytic nevi do not show experimental evidence for a malignant phenotype," American Journal of Pathology, vol. 136, no. 4, pp. 817-829, 1990.

[12] W. Baader, R. Kropp, and D. Tapper, "Congenital malignant melanoma," Plastic and Reconstructive Surgery, vol. 90, no. 1, pp. 53-56, 1992. 
[13] N. Ishii, S. Ichiyama, S. Saito, T. Kurosawa, and H. Nakajima, "Congenital malignant melanoma," British Journal of Dermatology, vol. 124, no. 5, pp. 492-494, 1991.

[14] T. Koyama, M. Murakami, O. Nishihara, and T. Masuda, "Congenital melanoma: a case suggesting rhabdomyogenic differentiation," Pediatric Dermatology, vol. 13, no. 5, pp. 389-393, 1996.

[15] F. P. Weber, E. Schwarz, and R. Hellenschmeid, "Spontaneous inoculation of melanotic sarcoma from mother to fetus," British Medical Journal, vol. 1, pp. 529-537, 1930.

[16] E. Holland, "A case of transplacental metastasis of malignant melanoma from mother to fetus," British Journal of Obstetrics and Gynaecology, vol. 56, pp. 529-536, 1949.

[17] H. W. Dargeon, J. W. Eversole, and V. Del Duca, "Malignant melanoma in an infant," Cancer, vol. 3, article 299, 1950.

[18] I. Brodsky, M. Baren, S. B. Kahn, G. Lewis, and M. Tellem, "Metastatic malignant melanoma from mother to foetus," Cancer, vol. 18, pp. 1048-1054, 1965.

[19] G. Argenziano, G. Fabbrocini, P. Carli, V. De Giorgi, E. Sammarco, and M. Delfino, "Epiluminescence microscopy for the diagnosis of doubtful melanocytic skin lesions: comparison of the ABCD rule of dermatoscopy and a new 7-point checklist based on pattern analysis," Archives of Dermatology, vol. 134, no. 12, pp. 1563-1570, 1998.

[20] J. C. Alper and L. B. Holmes, "The incidence and significance of birthmarks on a cohort of 4,641 newborns," Pediatric Dermatology, vol. 1, no. 1, pp. 58-68, 1983.

[21] F. V. Bittencourt, A. A. Marghoob, A. W. Kopf, K. L. Koenig, and R. S. Bart, "Large congenital melanocytic nevi and the risk for development of malignant melanoma and neurocutaneous melanocytosis," Pediatrics, vol. 106, no. 4 I, pp. 736-741, 2000.

[22] P. A. Phadke, D. Rakheja, L. P. Le et al., "Proliferative nodules arising within congenital melanocytic nevi: a histologic, immunohistochemical, and molecular analyses of 43 cases," American Journal of Surgical Pathology, vol. 35, no. 5, pp. 656-669, 2011.

[23] G. Collina, S. Deen, S. Cliff, P. Jackson, and M. G. Cook, "Atypical dermal nodules in benign melanocytic naevi," Histopathology, vol. 31, no. 1, pp. 97-101, 1997.

[24] R. J. Reed, H. Ichinose, W. H. Clark, and M. C. Mihm, "Common and uncommon melanocytic nevi and borderline melanomas," Seminars in Oncology, vol. 2, no. 2, pp. 119-147, 1975.

[25] D. E. Elder and G. F. Murphy, Atlas of Tumor Pathology: Melanocytic Tumors of the Skin, Armed Forces Institute of Pathology, Washington, DC, USA, 1991.

[26] J. F. Altman, L. Lowe, B. Redman et al., "Placental metastasis of maternal melanoma," Journal of the American Academy of Dermatology, vol. 49, no. 6, pp. 1150-1154, 2003.

[27] J. F. Anderson, S. Kent, and G. A. Machin, "Maternal malignant melanoma with placental metastasis: a case report with literature review," Pediatric Pathology, vol. 9, no. 1, pp. 35-42, 1989.

[28] R. D. W. Marsh and N. M. Chu, "Placental metastasis from primary ocular melanoma: a case report," American Journal of Obstetrics and Gynecology, vol. 174, no. 5, pp. 1654-1655, 1996.

[29] S. N. Leech, H. Bell, N. Leonard et al., "Neonatal giant congenital nevi with proliferative nodules: a clinicopathologic study and literature review of neonatal melanoma," Archives of Dermatology, vol. 140, no. 1, pp. 83-88, 2004.

[30] D. Angelucci, P. G. Natali, P. L. Amerio, M. Ramenghi, and P. Musiani, "Rapid perinatal growth mimicking malignant transformation in a giant congenital melanocytic nevus," Human Pathology, vol. 22, no. 3, pp. 297-301, 1991.
[31] C. B. Carroll, P. Ceballos, A. E. Perry, M. C. Mihm, and S. K. Spencer, "Severely atypical medium-sized congenital nevus with widespread satellitosis and placental deposits in a neonate: the problem of congenital melanoma and its simulants," Journal of the American Academy of Dermatology, vol. 30, no. 5, pp. 825-828, 1994.

[32] J. Borbujo, M. Jara, L. Cortes, and L. S. De, "A newborn with nodular ulcerated lesion on a giant congenital nevus," Pediatric Dermatology, vol. 17, no. 4, pp. 299-301, 2000.

[33] G. Argenziano, H. P. Soyer, S. Chimenti et al., "Dermoscopy of pigmented skin lesions: results of a consensus meeting via the internet," Journal of the American Academy of Dermatology, vol. 48, no. 5, pp. 679-693, 2003. 


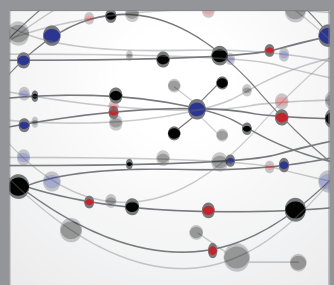

The Scientific World Journal
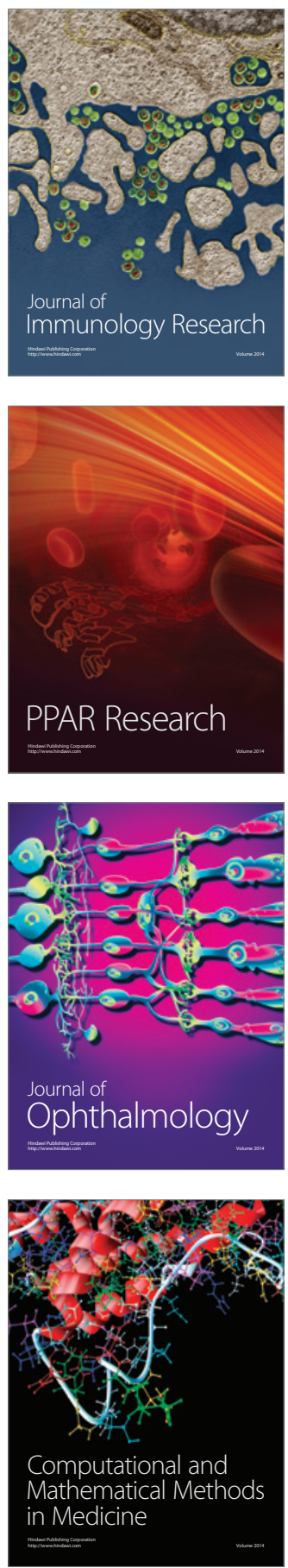

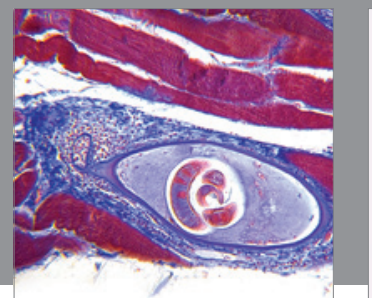

Gastroenterology

Research and Practice
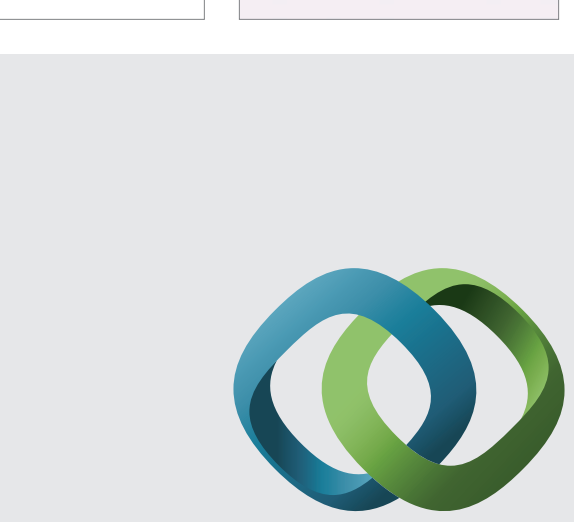

\section{Hindawi}

Submit your manuscripts at

http://www.hindawi.com
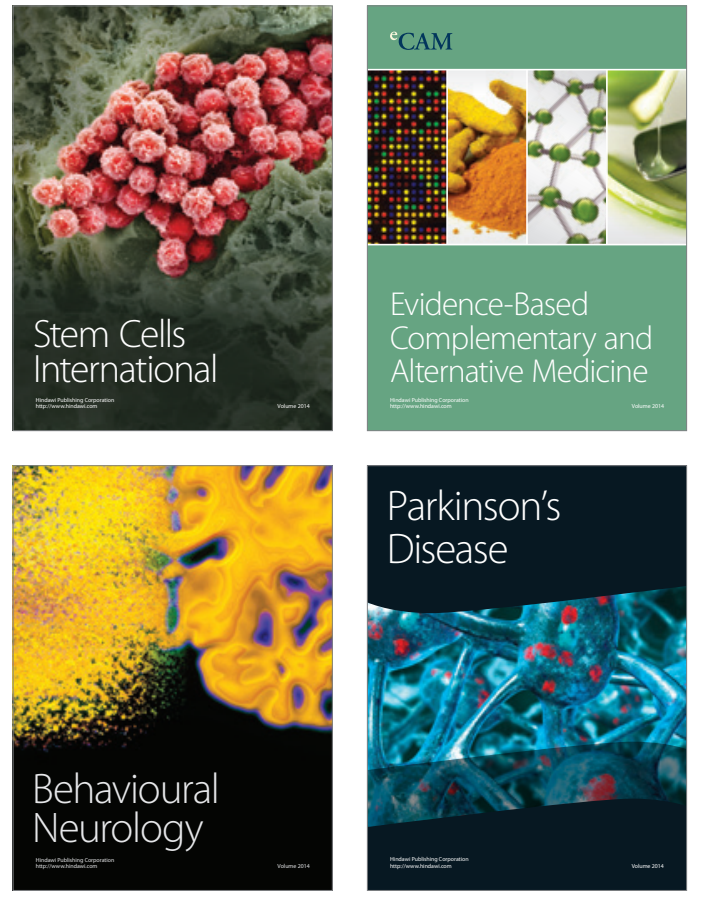
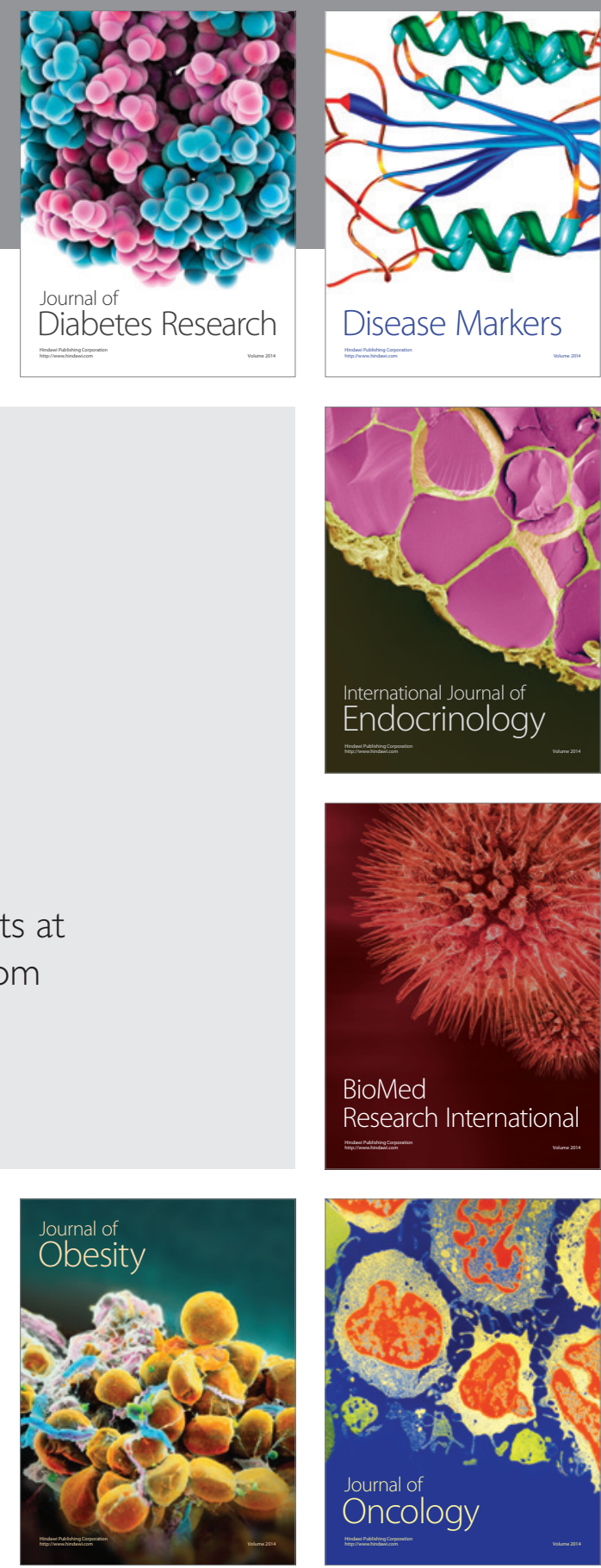

Disease Markers
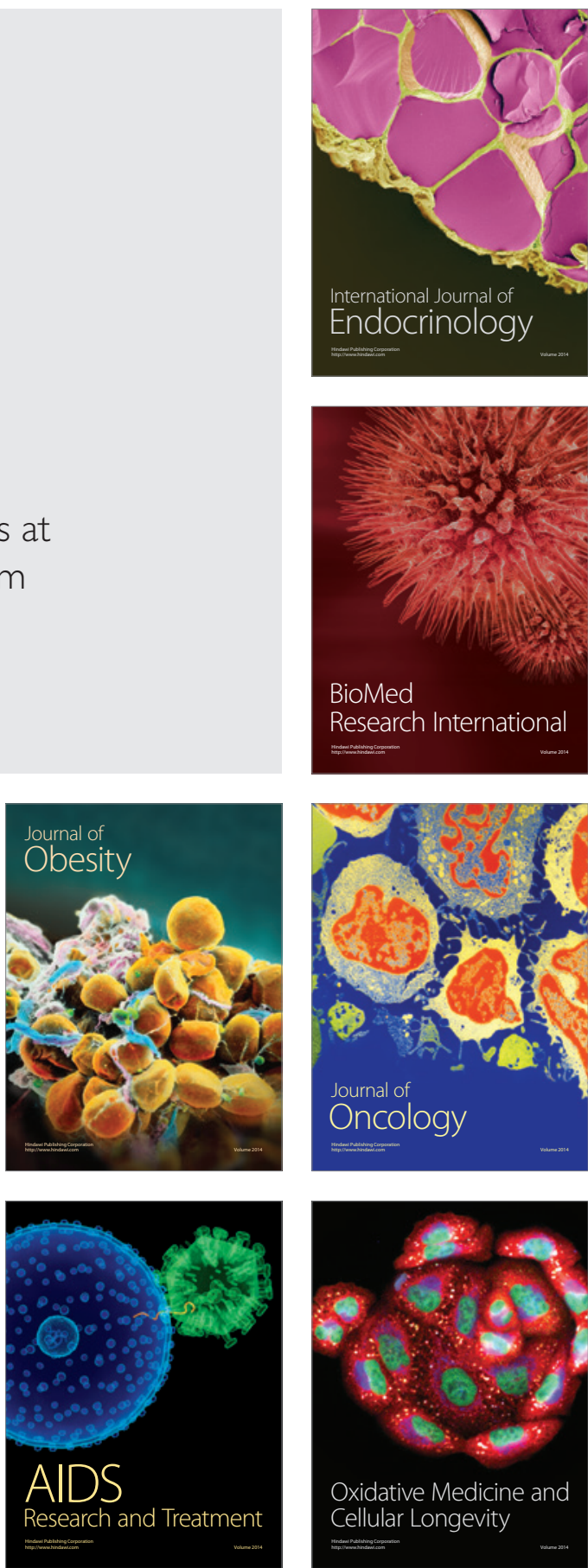